\title{
Meeting Report: The First National Academies Summer Institute for Undergraduate Education in Biology
}

\author{
William Wood*, ${ }^{*}$ and James Gentile**
}

\author{
*Department of MCD Biology, University of Colorado, Boulder, CO; **Department of Biology, Hope College, \\ Holland, MI
}

Submitted October 1, 2003; Accepted October 1, 2003

\begin{abstract}
The 2002 NRC Report Bio2010 (NRC, 2003), calling for changes in undergraduate education for biologists, suggested the establishment of summer workshops to help implement reform. While the report was in press, Millard Susman, a retired genetics professor at the University of Wisconsin, Madison, and Bob Yuan, a professor at University of Maryland-College Park who also works as a consultant for the National Research Council's (NRC) Board on Life Sciences, came up with an interesting idea about the form such workshops might take. Both had participated in and had been inspired by the well known Cold Spring Harbor Laboratory Courses on specific research areas in molecular biology and genetics. Why not create a summer institute modeled on these courses, but focused on education? Students and instructors would spend together a few days of intensive lectures, seminars, and laboratory work, but with the goal of learning about new researchbased ways to improve undergraduate biology teaching at large universities rather than learning about a new area of biological research. The "student" participants would be primarily junior biology faculty from Research I institutions; the "instructor" facilitators would be accomplished biological scientists who had also distinguished themselves as educators. Yuan took the idea to National Academies President Bruce Alberts, whose enthusiastic response led to formation of an NRC Committee to implement the proposal. The two of us were appointed as co-chairs, with Kerry Brenner of the NRC as Study Director. ${ }^{1}$
\end{abstract}

Serious planning for the first Institute began in early 2003, with help from other NRC staff, as well as faculty members from the Center for Biology Education at UW Madison, ${ }^{2}$ which had agreed to host the Institute. The committee agreed that the first Institute should be a pilot, to test the idea that the intellectual intensity and excitement of a Cold Spring Harbor

DOI: $10-1187 /$ cbe.03-10-0042

+Corresponding author. E-mail address: wood@stripe.colorado. edu.

${ }^{1}$ Other members of the committee are Amy Chang, Chair of the Education Board for the American Society for Microbiology, Jo Handelsman, HHMI Professor of Plant Pathology at UW Madison, and Ishrat Khan, Professor of Biology at Clark Atlanta University. ${ }^{2}$ Other ad hoc committee members instrumental in the planning process were Millard Susman and Lillian Tong of the UW Madison Center for Biology Education, and Bob DeHaan, Jay Labov, and Bob Yuan of the NRC. course could be generated among participants in a workshop on life sciences pedagogy. About a third of the 37 participants invited by the committee to attend were prominent biological scientists already involved in improving undergraduate teaching and learning, primarily at large research universities. ${ }^{3}$ Four were Howard Hughes Medical Institute (HHMI) professors. ${ }^{4}$ The group also included biology educators and science educators from other fields, as well as representatives from $\mathrm{HHMI}, \mathrm{NRC}$, and the National Institute of General Medical Sciences (NIGMS). Finally there were three assistant professors from biological science departments at UW Madison, representing the "students" to which future Institutes would be directed. All participants shared a strong interest in undergraduate teaching and how to improve it.

The pilot Institute was designed around several principles:

- teachers, like students, learn by doing;

- we must model the teaching practices we teach about;

- scientists like to be involved in applying new concepts; and

- educators like to leave a meeting with "products" (i.e., specific applicable tools, and not simply new ideas).

Consequently, much of the meeting consisted of workshop sessions, in which individuals or teams of participants modeled their favorite simple participatory laboratory or classroom exercises, involving the entire group acting as students. These presentations were followed by lively discussion of whether and why the exercise was effective as a teaching tool, and how this tool could be adapted at other institutions.

Recent research findings on student learning and how to enhance it (NRC, 1999, 2000, 2002) were emphasized throughout the conference. A major topic of discussion was how to raise awareness of these findings among faculty colleagues, and how to persuade them to participate in efforts to improve teaching and learning. Several sessions included small group

\footnotetext{
${ }^{3} \mathrm{~A}$ complete list of meeting participants with biographical sketches can be viewed at the Institute web site, http://www. AcademiesSummerInstitute.org.

${ }^{4}$ Bob Goldberg, UCLA, Jo Handelsman, UW-Madison, Ron Hoy, Cornell, and Graham Walker, MIT. The HHMI professorships, each with research-scale funding of $\$ 1 \mathrm{M}$ over four years, were awarded in 2001 to twenty outstanding researcher-educators, for development of innovative teaching programs and materials that would integrate their research with teaching. See Cech, T. R. (2003). Rebalancing teaching and research, Science 299, 165.
} 

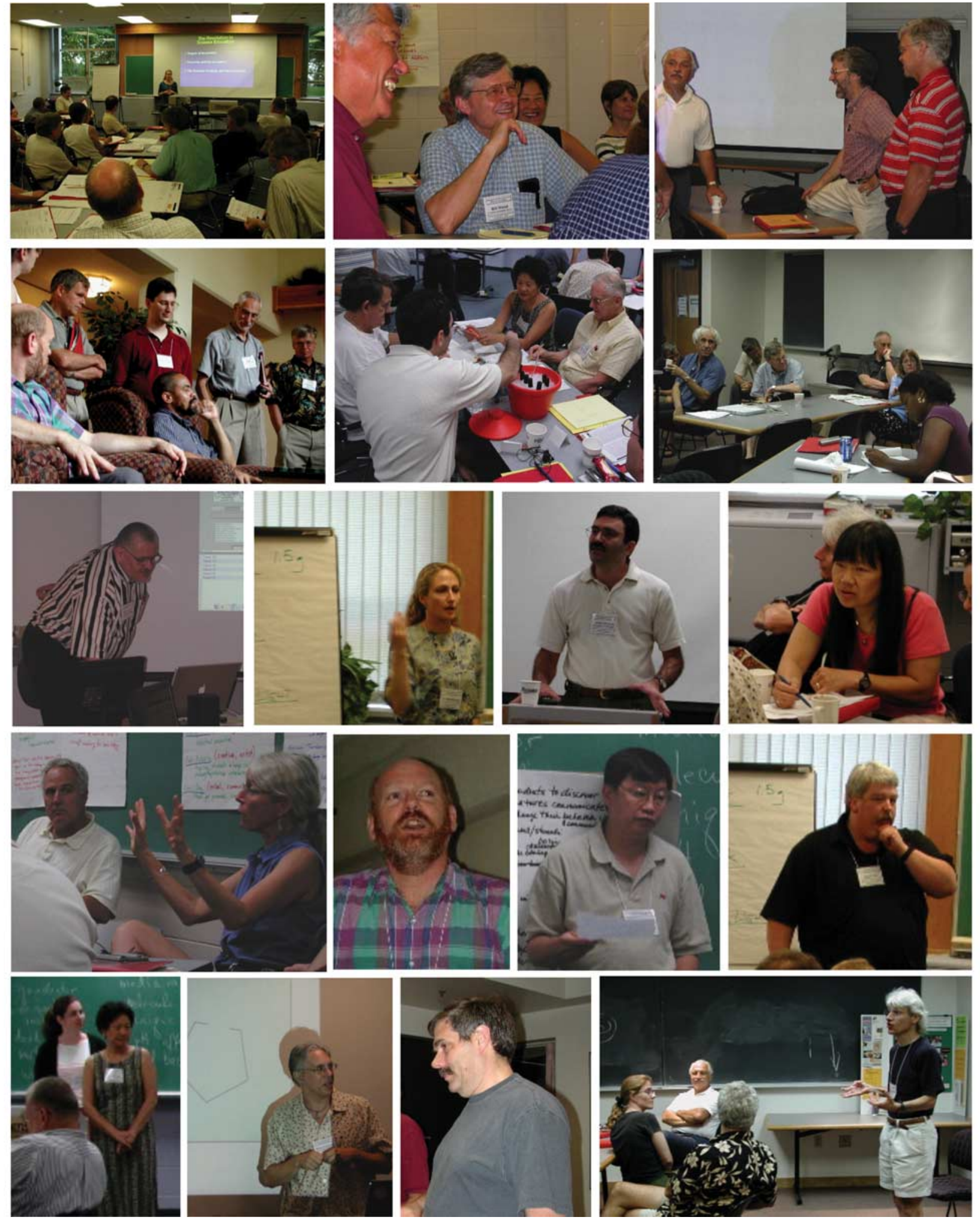

Top row (facing camera, left to right): Jo Handelsman kicks off the conference, Bob Yuan, Bill Wood, Amy Chang, Kathy Frame, Jim Gentile, Graham Walker, Neil Baker; second row: Bob Beichner, Peter Bruns, Adam Fagen, Derrick Tabor (seated), Bob DeHaan, Neil Baker, Millard Susman, Amy Chang, Jack Kampmeier, Michael Gaines, John Roth, Bill Wood, Paul Williams, Pat Pukkila, Vanee Vines; third row: John Jungck, Jo Handelsman, Dan Klionsky, Lillian Tong; fourth row: Richard Cyr, Diane Ebert-May, Bob Beichner, Ron Hoy, Bob Full; fifth row: Kerry Brenner, Amy Chang, Mike Klymkowsky, Jay Labov, Laura Knoll, Jim Gentile, Bob Goldberg. 
discussions followed by reporting back to the conference: on interdisciplinary teaching, balancing the teaching of content and analytical thinking, effective use of information technology in classrooms and laboratory environments (particularly for very large classes), and finally, how to organize and structure future workshops to make them an effective use of faculty time.

Some of the most exciting sessions began with lecture presentations about successful course transformations and research-based courses-a reminder that the goal of teaching reform should not be to eliminate lecturing (Powell, 2003), but simply to use it more judiciously, as an inspirational tool rather than a primary means of transmitting information.

The success of this first Institute exceeded our expectations. Several participants said it was the most exciting meeting they had attended for some time. Perhaps most important, the three assistant professors from UW Madison were all enthusiastic, agreeing that they found the Institute tremendously valuable and would have benefited even more had they attended such a meeting when they were first faced with the teaching of undergraduates.

Encouraged by this success, the committee has begun planning for future Institutes, under the auspices of what will be called the National Academies Summer Institute on Undergraduate Education in Biology. The courses will bring together each summer in Madison a small group of prominent scientist-educators (Institute facilitators) with both junior and senior life sciences faculty members, primarily from large research universities (participants), who wish to develop more effective teaching methods for their own classes and their institutions. Together the Institute facilitators and participants will engage in several days of intensive presentations, demonstrations, and hands-on workshops. Prospective participants will be encouraged to apply as teams, for example, a junior and a senior faculty member from the same campus. Admis- sion will be selective, based on written proposals for how applicants would benefit from and make use of the Institute experience. Another important component of the application process will be a letter from a Dean or Department Chair promising a financial contribution to support the attendance of the applicants from that institution, as well as substantive support for subsequent implementation, at the home institution, of what was learned at the Institute. The graduates of these courses, to be given an honorific title by the National Academies for one year following their participation, will be obligated to promote efforts to improve undergraduate biology courses, working with their colleagues at home and through their disciplinary societies. We believe that the Summer Institute on Education in Biology can have a ripple effect that could lead to major widespread improvement in undergraduate biology instruction. ${ }^{5}$

\section{REFERENCES}

Cech, T.R. (2003). Rebalancing teaching and research, Science 299, 165

National Research Council. (1999). How People Learn: Brain, Mind, Experience, and School. Washington, DC, National Academy Press.

National Research Council. (2000). How People Learn: Bridging Research and Practice. Washington, DC, National Academy Press.

National Research Council. (2002). Learning and Understanding: Improving Advanced Study of Mathematics and Science in U.S. High Schools. Washington, DC, National Academy Press.

National Research Council. (2003). Bio2010: Transforming Undergraduate Education for Future Research Biologists. Washington, DC, National Academy Press.

Powell, K. (2003). Science education: spare me the lecture. Nature 425, 234-236.

\footnotetext{
${ }^{5}$ More information about the Institute and application procedures for next year's course can be found at http://www. AcademiesSummerInstitute.org. See also in this issue the feature "Education at the National Academies" by J. Labov, whom we thank for advice and suggestions during preparation of this report.
} 